\title{
New Health Minister addresses BFS Conference
}

The recently appointed Minister for

Health, Maria Caulfield MP, addressed

delegates at the British Fluoridation

Society (BFS) conference in Birmingham in October.

The event was held at the University of Birmingham's new School of Dentistry and focused on 'Making a Difference'.

In a welcome speech by video link, the minister anticipated a period of joint working between the Department of Health and Social Care and the BFS, stated that there has been significant improvement in oral health over the last 40 years, and also acknowledged that substantial inequalities remain.

Mrs Caulfield said: 'All tap water in England contains some fluoride and the benefits of water fluoridation are not dependent on changing personal behaviour and therefore benefits those at risk, for whatever reason, most'.

The minister also said she was committed to working with people at the conference and across the dental sector going forward.

Lord Hunt, former Minister of Health, Labour peer and President of the BFS, officially opened the conference.

During the event, delegates also heard from a range of experts and key speakers exploring how water fluoridation is entering a new era in its implementation to reduce dental inequalities. They included: Anna Ireland, National Lead for Dental Public Health; Eddie Crouch, Chair of the Principal Executive Committee of the British Dental Association (BDA); Sandra White, Clinical Director, Association of Dental Groups; Maria Morgan, President of the British Association for the Study of Community Dentistry (BASCD); Fiona Ellwood, Executive Director of the Society of British Dental Nurses; and Yewande Oduwole and Victoria Ojetunde, young dentists with an interest in social media.
A recurring theme was the importance of engaging with the wider dental profession and young people in particular, who favour the use of social media for news and information sharing.

The health minister also said that fluoridation opponents tend to make statements based on myths and rumours, not evidence-based, and we need to equip ourselves to deal with this.

BFS chair, Dr Barry Cockcroft CBE, said: 'It was great to hear the minister and a spokesman for the Labour Party both being positive about water fluoridation.

'The conference provided an important opportunity to bring the dental community together to explore how everyone that is committed to reducing dental health inequalities can work together to make water fluoridation happen. We need to push its relevance and make it part of the conversation for us all. 